\title{
RELAÇÃO MÃE-CUIDADORES DE GEMELARES NO PRIMEIRO ANO APÓS O NASCIMENTO
}

\author{
MOTHER-CAREGIVERS TWINS RELATIONSHIP \\ IN THE FIRST YEAR AFTER BIRTH
}

Marta Knijnik Lucion ${ }^{1}$ Norma Escosteguy ${ }^{1}$

Lucion MK e Escosteguy N. Relação Mãe/Cuidadores-Gemelares no Primeiro Ano Após o Nascimento. Rev Bras Cresc e Desenv Hum 2011; 21(2): 207-318.

\section{RESUMO}

As relações precoces do bebê, principalmente de zero a três anos, são fundamentais para o desenvolvimento e estruturação da personalidade. O objetivo deste projeto foi observar as interações entre mãe/cuidadores-gemelares, dos gêmeos entre si e identificar fatores que influenciam o desenvolvimento dos gêmeos no primeiro ano de vida. Quatro gestantes foram acompanhadas desde o parto até os gêmeos completarem um ano. Foram realizadas cinco filmagens dos bebês e seus cuidadores com duração de aproximadamente quarenta minutos e intervalos de três meses entre cada uma, iniciando no dia do parto. As filmagens foram analisadas pelas autoras do trabalho e variáveis qualitativas, como a qualidade e peculiaridades dos vínculos e do desenvolvimento dos gêmeos, foram avaliadas. O estudo evidenciou que a qualidade do vínculo parental influi no desenvolvimento dos gemelares durante o primeiro ano de vida, destacando que eles necessitam ser nutridos afetivamente por cuidadores adultos. Observaram-se escassas interações dos gêmeos entre si durante o período do estudo, reforçando a importância das relações com os cuidadores.

Palavras-chave: gêmeos; relação mãe-gemelar; interações; desenvolvimento precoce; cuidado maternal.

1 Departamento de Psiquiatria da Faculdade de Medicina da Pontifícia Universidade Católica do Rio Grande do Sul (PUCRS). Av. Ipiranga, 6690 sala 309 - Porto Alegre - RS - CEP 90160-090.

Trabalho realizado no serviço de psiquiatria do Hospital São Lucas da PUCRS.

Correspondência para: Marta Knijnik Lucion. Rua Prof. Ulisses Cabral, 550. Chácara das Pedras. Porto Alegre, RS. CEP: 91330-520. Fone: 98351491. Fone/fax: 33344015 - E-mail: martaklu@gmail.com 


\begin{abstract}
The early relationships, especially from zero to 3 years old, are crucial for the development and structuring of the personality. The present project aims to analyze the relationship between twins and their caregivers and twins between themselves, and identify factors that could influence the development of the twins during the first year of life. Four pregnant women were followed since the birth of the twins until they have completed one year. Five video recordings of the caregivers with the babies, with about forty minutes each, were obtained with an interval of three months from each other, starting on the day of birth of the twins. The recordings were analyzed by the authors and qualitative variables, such as the quality and the peculiarities of the bond and the development of twins, were evaluated. The project pointed that the quality of the parental bonding influences twin development, showing that they need to be affectively nurtured by adults caregivers. Few interactions between the twins were observed during the period studied, reinforcing the importance of the relationship with the caregivers.
\end{abstract}

Key words: twins; mother-twins relationship; early development; bond, interaction.

\section{INTRODUÇ̃̃̃}

Fatores genéticos, ambientais e vivências infantis constituem a personalidade ${ }^{1}$. Várias pesquisas recentes mostram que fatores ambientais, como o estresse, podem influenciar a carga genética alternando, por exemplo, a expressão gênica e assim alterar o fenótipo do indivíduo ${ }^{2}$. De fato, componentes genéticos predisponentes têm sido relacionados a transtornos psiquiátricos e a características de temperamento ${ }^{3}$. Esse efeito ambiental é mais marcante no início da vida.

Já na segunda metade do século XX teóricos da psicanálise como Winnicott e Melanie Klein destacavam a importância dos primeiros anos de vida para o desenvolvimento da personalidade $^{4,5}$. A Classificação Diagnóstico Zero a Três reforça a importância dessa etapa e os relacionamentos vivenciados nesse período para o desenvolvimento da personalidade e estrutura de defesas psicológicas ${ }^{6}$. O cérebro humano apresenta plasticidade importante antes dos três anos. Especialmente até os 18 meses, o cérebro apresenta crescimento e organização neuronal significativo e esses momentos de maior desenvolvimento e estruturação neuronal são conhecidos como períodos críticos. Alterações nessas etapas da vida influenciam o desenvolvimento e bem estar da criança a longo prazo ${ }^{7}$.

As interações precoces exercem papel central no desenvolvimento cerebral. Brincadeiras ativam o sistema nervoso simpático dos bebês, desencadeando uma cascata biológica na qual noradrenalina e endorfinas são liberadas, assim aumentando as suas sensações positivas ${ }^{8,9}$.

A relação mãe-bebê é uma interação delicada e de extrema importância para a formação psicológica do individuo. Para Winnicott, o primeiro ambiente que se constitui para o bebê é a mãe . O ambiente/mãe não pode ser totalmente responsabilizado pelo que sucede em termos de saúde mental do bebê, mas ele pode influenciar decisivamente, de maneira positiva ou negativa, o desenvolvimento psicológico desse.

Inegavelmente, se cuidar de um recémnascido é um desafio; cuidar de dois simultaneamente se torna um desafio maior ainda. A mãe agora passa a atender às necessidades de dois bebês, que deverão formar personalidades dife- 
rentes e que apresentam, portanto, necessidades distintas ${ }^{10}$. Na experiência de Winnicott, a maioria das mães de gemelares se pudesse preferiria ter escolhido não ter gêmeos, o que sugere as dificuldades dessa situação ${ }^{4}$. A idéia de ser uma mãe "suficientemente boa" para dois bebês pode ser assustadora para a gestante. Além disso, gestações gemelares estão mais associadas a complicações perinatais, tanto fetais quanto maternas ${ }^{11}$, fato que também pode interferir no estabelecimento de relações precoces.

Existem limitadas pesquisas a respeito da relação precoce mãe-gêmeos. No entanto, a importância das relações interpessoais precoces e a crescente incidência de gestações gemelares evidenciam a importância de estudos sobre a relação mãe-gemelares.

Desta maneira, o objetivo é descrever a interação entre os gemelares e seus cuidadores e entre os próprios gêmeos durante o $1^{\circ}$ ano de vida, bem como identificar as influências das interrelações precoces na formação das características específicas para a constituição da individualidade dos gemelares.

\section{MÉTODO}

A proposta deste estudo exploratório foi realizar a observação seriada da interação mãe/ cuidadores-gemelares. Entre abril e setembro de 2009, gestantes de gemelares que realizavam acompanhamento no ambulatório de obstetrícia do Hospital São Lucas da Pontifícia Universidade Católica do Rio Grande do Sul (HSL-PUCRS) foram convidadas a participar do estudo, conforme sua adequação aos critérios de inclusão e exclusão.

A seleção da amostra foi por conveniência, não sendo homogeneizada. As variáveis sociodemográficas foram registradas, mas a participação na pesquisa não foi limitada pelo nível socioeconômico, número de filhos, participação ou não de programas de fertilidade e situações conjugais distintas.

\section{Critérios de inclusão:}

- nascimento de gemelares com 34 semanas ou mais;

- morar em Porto Alegre ou grande Porto Alegre;

- aceitar o consentimento informado, contendo o projeto de seguimento durante o $1^{\circ}$ ano de vida.

\section{Critérios de exclusão:}

- mães com menos de 18 anos;

- doenças genéticas ou malformações importantes que requeiram período de internação em unidade de tratamento intensivo maior que 60 dias ou cirurgia de grande porte.

Os participantes realizaram seis encontros. O primeiro consistiu em uma entrevista semi-estruturada com a gestante no mínimo duas semanas antes do parto, onde o termo de consentimento livre e esclarecido foi apresentado e assinado. O segundo encontro, que durava cerca de vinte minutos, ocorreu no hospital no primeiro dia de vida dos gêmeos, sendo esse registrado em filmadora.

Após a alta hospitalar foram realizadas quatros visitas domiciliares às famílias. Cada visita durou cerca de quarenta minutos e foi filmada por um auxiliar de pesquisa. Os encontros ocorreram aos três, seis, nove e doze meses dos gêmeos. As datas foram previamente definidas por serem datas com marcos de desenvolvimento neuropsicomotor. Uma cópia das filmagens foi entregue às mães após o término da pesquisa.

Após cada encontro preencheu-se um protocolo. Esse era específico para cada visita, contemplando dados importantes a cada faixa etária dos bebês como alimentação, motricidade, linguagem, brincadeiras e interações entre os gemelares.

Todos os protocolos avaliam a preferência dos cuidadores pelos gêmeos, características do conteúdo verbal dos cuidadores e 
critérios utilizados na Classificação Zero a Três para qualificar o relacionamento paisbebês - qualidade comportamental da interação, tom afetivo e envolvimento psicológico.

O projeto foi aprovado pelo comitê de ética do HSL-PUCRS, protocolo 09/04551.

\section{RESULTADOS}

Os resultados são apresentados através de duas tabelas e um gráfico relativo ao clima afetivo identificado ao longo da observação.

A tabela 1 apresenta características da estruturação familiar. Dentre as gestantes de gemelares em acompanhamento no ambulatório de obstétrica do HSL-PUCRS no período de 1 de abril de 2009 a 30 de setembro de 2009, treze preencheram critérios para serem incluídas na pesquisa. Dessas treze, apenas cinco aceitaram participar do projeto. Uma das gestantes foi observada após o nascimento e aos seis meses dos gêmeos, perdendo-se o contato após essa data. Essa foi excluída do grupo de análise. As quatro participantes que constituem a amostra apresentam nível socioeconômico semelhante.

A tabela 2 sintetiza dados obstétricos e pediátricos dos gêmeos. Nenhuma das gestantes da amostra participou de programa de fer-

Tabela 1: Estruturação Familiar dos /Gemelares em Acompanhamento Ambulatorial de Obstetrícia

\begin{tabular}{|c|c|c|c|c|c|}
\hline Caso & $\begin{array}{c}\text { Idade } \\
\text { materna } \\
\text { (anos) }\end{array}$ & $\begin{array}{l}\text { Presença de } \\
\text { companheiro }\end{array}$ & $\begin{array}{l}\text { Outrosfilhos } \\
\text { (idade) }\end{array}$ & $\begin{array}{l}\text { Outros } \\
\text { cuidadores }\end{array}$ & $\begin{array}{c}\text { Emprego } \\
\text { materno }\end{array}$ \\
\hline 1 & 37 & Sim & $\begin{array}{c}5(19,15,12 \\
\text { gêmeos e } 10 \\
\text { anos) - todos de } \\
\text { relacionamento } \\
\quad \text { anterior }\end{array}$ & Babá & $\begin{array}{l}\text { Inicia } \\
\text { quando } \\
\text { gêmeos } \\
\text { completam } \\
3 \text { meses }\end{array}$ \\
\hline 2 & 39 & Sim & $\begin{array}{l}1 \text { (19 anos) - de } \\
\text { relacionamento } \\
\text { anterior }\end{array}$ & Não & Não \\
\hline 3 & 18 & Não & Não & $\begin{array}{l}\text { Avós } \\
\text { maternos } \\
\text { e tios }\end{array}$ & Não \\
\hline 4 & 25 & Sim & $\begin{array}{c}2 \text { (6 e } 2 \text { anos) } \\
\text { - a mais velha de } \\
\text { relacionamento } \\
\text { prévio e a outra } \\
\text { com } \\
\text { companheiro } \\
\text { atual }\end{array}$ & $\begin{array}{l}\text { A partir do } \\
\text { décimo mês: } \\
\text { babá }\end{array}$ & $\begin{array}{c}\text { Inicia } \\
\text { quando } \\
\text { gêmeos } \\
\text { completam } \\
10 \text { meses }\end{array}$ \\
\hline
\end{tabular}


tilização e nenhuma das gestações foi planejada. Todos os gêmeos são dizigóticos.

O gráfico 1 mostra a variação do clima afetivo nas famílias a cada visita. O caso 1 iniciou com conflito conjugal no nascimento dos gêmeos, que pareceu se resolver ao longo do primeiro ano, melhorando gradualmente $o$ clima afetivo do ambiente familiar. No caso 2 o clima afetivo se manteve estável ao longo de toda a pesquisa. No caso 3 o clima afetivo permaneceu entre ruim e moderado. No caso 4, a mãe mostrou-se sobrecarregada com a gemelidade. O clima afetivo apresentou melhora significativa quando ela volta a trabalhar, introduzindo uma nova cuidadora para as crianças.

Tabela 2: Dados Obstétricos e Pediátricos de Gemelares em Acompanhamento Obstétrico

\begin{tabular}{|c|c|c|c|c|c|c|}
\hline Caso & $\begin{array}{c}\text { Gestação/IG } \\
\text { semanas/ } \\
\text { Via do parto }\end{array}$ & Apgar & Sexo & $\begin{array}{c}\text { Peso ao } \\
\text { nascer } \\
\text { (gramas) }\end{array}$ & $\begin{array}{c}\text { Peso aos doze } \\
\text { meses } \\
\text { (gramas) }\end{array}$ & $\begin{array}{c}\text { Aleitamento } \\
\text { materno }\end{array}$ \\
\hline 1 & $\begin{array}{c}6^{\mathrm{a}} \\
38 / \text { vaginal }\end{array}$ & $\begin{array}{l}\text { A1: } 9 / 10 \\
\text { B1: } 7 / 9\end{array}$ & $\begin{array}{l}\mathrm{A} 10^{\prime \prime} \\
\mathrm{B} 1 \mathrm{O}^{\prime \prime}\end{array}$ & $\begin{array}{l}\text { A1: } 3010 \\
\text { B2: } 3250\end{array}$ & $\begin{array}{c}\text { A1: } 11.500 \\
\text { B1: } 9.400\end{array}$ & $\begin{array}{l}\text { "A1" parou de ser } \\
\text { amamentado por } \\
\text { volta dos } 6 \\
\text { meses. "B1" } \\
\text { persistia com } \\
\text { amamentação na } \\
\text { visita dos } 12 \\
\text { meses }\end{array}$ \\
\hline 2 & $\begin{array}{c}2^{a} \\
35 / \text { cesariana }\end{array}$ & $\begin{array}{l}\text { A2: } 5 / 9 \\
\text { B2:5/9 }\end{array}$ & $\begin{array}{l}\mathrm{A} 2 \% \\
\mathrm{~B} 2 \%\end{array}$ & $\begin{array}{l}\text { A2: } 2200 \\
\text { B2: } 2030\end{array}$ & $\begin{array}{l}\text { A2: } 9.000^{*} \\
\text { B2: } 9.000^{*}\end{array}$ & $\begin{array}{c}\text { Contraindicado } \\
\text { por patologia } \\
\text { materna }\end{array}$ \\
\hline 3 & $\begin{array}{c}1^{\mathrm{a}} \\
38 / \text { cesariana }\end{array}$ & $\begin{array}{l}\text { A3: } 9 / 10 \\
\text { B3: } 9 / 10\end{array}$ & $\begin{array}{l}\mathrm{A} 30^{\prime} \\
\mathrm{B} 3 \text { 우 }\end{array}$ & $\begin{array}{l}\text { A3: } 2840 \\
\text { B3: } 2375\end{array}$ & $\begin{array}{l}\mathrm{A} 3 * * \\
\mathrm{~B} 3 * *\end{array}$ & $\begin{array}{l}\text { Nunca obtiveram } \\
\text { aleitamento } \\
\text { materno } \\
\text { exclusivo. } \\
\text { Aleitamento } \\
\text { suspenso antes } \\
\text { dos } 3 \text { meses }\end{array}$ \\
\hline 4 & $\begin{array}{c}3^{\mathrm{a}} \\
38 / \text { vaginal }\end{array}$ & $\begin{array}{l}\text { A: } 10 / 10 \\
\text { B: } 10 / 10\end{array}$ & $\begin{array}{l}\mathrm{A} 4 \text { 우 } \\
\mathrm{B} 49\end{array}$ & $\begin{array}{l}\text { A4: } 2450 \\
\text { B4: } 2290\end{array}$ & $\begin{array}{l}\text { A4: } 10000^{*} \\
\text { B4: } 10000^{*}\end{array}$ & $\begin{array}{c}\text { Até os } 5 \\
\text { meses }\end{array}$ \\
\hline
\end{tabular}

Tabela 2: IG - Idade gestacional. "A" - primeiro gêmeo a nascer; "B" - segundo gêmeo.

* Peso aproximado, não soube precisar.

** Gêmeos não foram pesados nem aos 8, nem aos 12 meses - apresentam aparência eutrófica. 


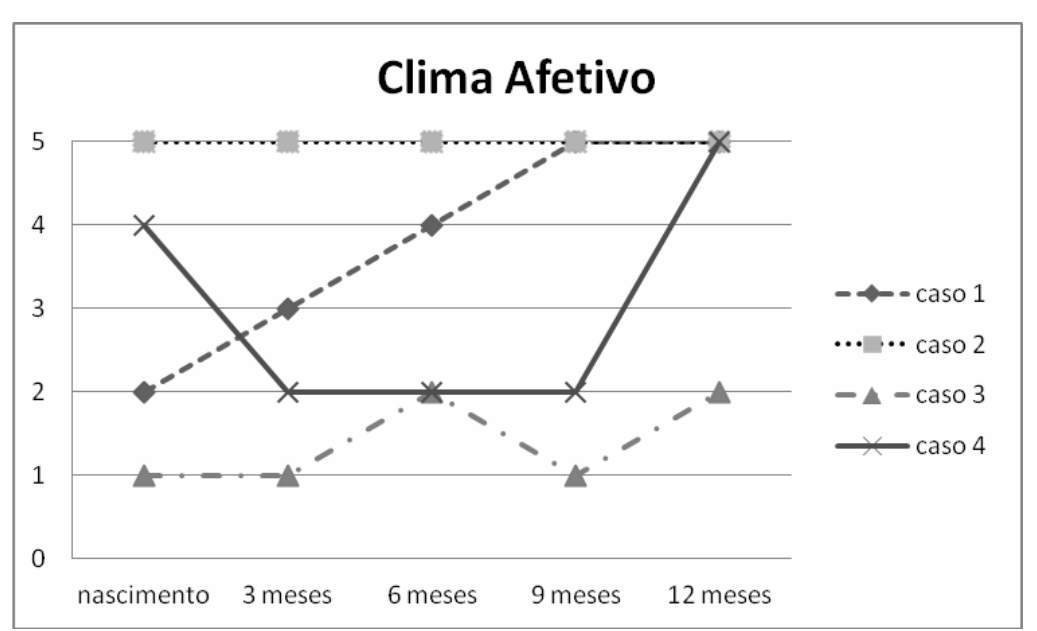

Figura 1: Gráfico do Clima Afetivo

5 , excelente; 4 , muito bom; 3 , bom; 2 , moderado e 1 , ruim.

\section{DISCUSSÃO}

O método utilizado apresenta algumas limitações. Por ser uma pesquisa observacional e qualitativa, está sujeita às influências da análise subjetiva. Tentou-se diminuir esse viés através das discussões das filmagens. A amostra, por ser pequena e por conveniência, também é uma limitação. Um dos possíveis motivos para o reduzido tamanho da amostra (nove recusas entre treze gestantes aptas) pode ser a duração do projeto e a insegurança das mães de aceitar essa observação ao longo de um ano.

Apesar das limitações, confirmam-se algumas idéias importantes sobre o desenvolvimento infantil precoce e se oportuniza a discussão sobre aspectos específicos da gemelidade.

\section{A IMPORTÂNCIA DO INVESTIMENTO PSÍQUICO DOS CUIDADORES NO PRI- MEIRO ANO APÓS O NASCIMENTO}

A presença dos gêmeos foi vivenciada de maneira distinta entre as quatro famílias participantes e entre seus membros.
Logo no início do acompanhamento do caso 1 ficou evidente a diferença da percepção desses filhos pela mãe e pelo pai. Esses eram os primeiros filhos com os quais o pai viveria junto e poderia acompanhar o crescimento diariamente. O pai observava profundamente seus filhos, procurava interpretá-los, entendê-los e estimulá-los. O investimento psíquico da mãe nos gêmeos era menor, suas descrições no início eram muito vagas, aprofundando gradualmente durante o primeiro ano de vida.

$\mathrm{Na}$ visita dos seis meses a mãe sentou próximo aos meninos o que não provocou reações por parte deles, nenhum procurou ou se virou para a mãe. No mesmo encontro, a presença do pai estimulou uma resposta dos gêmeos. O pai ofereceu seus braços esticados e ambos os filhos seguraram-se no pai e solicitaram o colo, sugerindo a diferença da relação de cada cuidador com os gêmeos. Em todas as visitas domiciliares o pai conversava com os filhos, que se mostravam atentos à sua presença. O casal diferenciava os gêmeos, eles eram vistos como dois indivíduos distintos com necessidades e temperamentos diferentes. O pai realizava atribuições no sentido de compreen- 
der os filhos: "o gênio é forte, mas o sentimental é mais fraco" referindo-se ao fato de B1 ficar doente quando o pai viajava a trabalho, "ele (A1) é mais homenzinho, mais independente". Também tentava descrever os gêmeos através de suas atribuições: "Ele é mais cabeça, acho que vai ser escritor ou algo assim" sobre A1 e "o B1 não tem papas na língua". Sempre havia brinquedos à disposição dos gêmeos, pelos quais demonstravam interesse. Os gêmeos do caso 1 desenvolveram-se de forma adequada, com um ano apresentavam boa capacidade motora e vivacidade.

No caso 2, o nascimento das gêmeas provocou uma mudança no comportamento da mãe. Nos contatos prévios ao parto ela mostrou-se séria, de poucas palavras e pobre interação, deixando uma impressão de distanciamento e restrição afetiva. Após o nascimento das meninas, que precisaram ficar internadas uma semana no hospital por prematuridade, ela mostrou um lado alegre e satisfeito. Notava-se uma alteração até mesmo em sua fisionomia que se tornou suave e disposta. Nos telefonemas para combinar as visitas, ela conversava longamente de forma animada.

Nos encontros ela falava das filhas com carinho, dizia de forma afetiva, olhando ternamente para as gêmeas: "tudo o que eu faço é observar elas". O pai somente apareceu na filmagem dos 12 meses; antes a mãe fazia referências sobre a interação dele com as meninas. $\mathrm{Na}$ visita em que esteve presente mostrou-se carinhoso com as filhas e bem inserido no contexto familiar. A segunda a nascer (B2) apresentava refluxo gastroesofágico, necessitando de cuidados especiais na alimentação. A mãe empenhou-se em minimizar o sofrimento da filha e otimizar o seu crescimento, criando uma cuidadosa rotina alimentar.

Também realizou, ela própria, fisioterapia motora com B2, que estava um pouco mais hipotônica que a irmã. Entre a visita dos três e seis meses, B2 apresentou aumento de peso e melhora parcial do refluxo gastroesofágico.
À medida que os resultados do investimento materno apareciam, a mãe demonstrava estar ainda mais recompensada e satisfeita com sua nova estrutura familiar. Na visita de seis meses, ela disse "tudo inverteu", afirmando que agora $\mathrm{B} 2$ era maior que A2 (apesar de o peso de $\mathrm{A} 2$ continuar mais elevado do que o de B2) e que as meninas haviam invertido os temperamentos "antes a $\mathrm{A} 2$ era mais risonha e a B2 resmungava mais, agora a A2 ficou baldosa e B2 está sempre bem".

De fato no encontro dos seis meses A2 solicitava o colo da mãe por resmungos, sendo atendida. Porém havia pouca interação entre mãe e filha enquanto A2 era carregada. B2 recebia menos colo, mas quando tinha o contato com a mãe esse era rico de interações. Enquanto a A2 permanecia no colo materno, $\mathrm{B} 2$ ria em resposta às intervenções verbais da mãe e movimentava os membros, excitada, deitada na cama. O cuidado físico materno também a alimentava psiquicamente, B2 parecia poder permanecer sozinha por estar bem nutrida afetivamente.

A mãe procurava diferenciar as meninas, atribuindo sentido a suas atitudes "a B2 tá sempre de bom humor, chega num limite e daí fica braba!", "a A2 é de lua”, "a A2 é mais extrovertida, já B2 gosta de brincar sozinha". A mãe apresentava ambivalência sobre a relação das gêmeas entre em si; ela verbalizava que gostaria muito que elas fossem amigas, porém a cada aproximação física entre as duas ela intervinha "B2 não judia da mana", "B2...não, não bate na mana", "tá vendo? a A2 até quer brincar com carinho, mas a B2 vem batendo". Em todas essas situações, quando havia contato físico entre as gêmeas, esse era ocasional, em nenhum momento houve indício que uma aproximou-se da outra ou atingiu a outra intencionalmente. Em todo acompanhamento a mãe conversava com as gêmeas que respondiam à sua presença.

Havia brinquedos a disposição em todas as visitas. Com um ano as meninas, apesar de 
vivazes e alegres, apresentavam atraso no desenvolvimento motor, não engatinhavam e apresentavam dificuldade para se virarem. Esse fato pode ser creditado a um conjunto de fatores: prematuridade, ficavam pouco no chão, pouco estimulo motor (mãe cuidava delas sozinha e antecipava os movimentos das filhas, auxiliando as a concluir a movimentação).

A família 3 foi a que mais despertou preocupação. Os gêmeos foram fruto de um namoro breve entre dois adolescentes que não mantiveram o relacionamento após a descoberta da gravidez. A mãe dos gêmeos, desde a primeira entrevista, se mostrou pouco envolvida com os filhos. Nos encontros subsequentes ela olhava pouco para os gêmeos, não falava com eles e fazia descrições pobres deles.

As atribuições de sentido eram escassas, ocorrendo apenas quando questionada. Diferenciava-os pouco e de forma inconsistente, como quando respondeu sobre as diferenças no temperamento dos dois: "ele é brabo", "ela é braba". Na visita de 6 meses há uma leve melhora na relação da mãe com os gêmeos, ela estava mais segura em cuidar deles. No encontro dos três meses ela não dava banho nos filhos por medo de eles escorregarem de sua mão; ao seis meses ela conseguia realizar esse tipo de cuidado.

O investimento psíquico fornecido pela mãe foi sempre pobre. Ela parecia ter recursos afetivos limitados. A mãe cuidava sozinha dos filhos durante o dia, recebendo ajuda da sua mãe e do seu padrasto à noite. Os tios de $15 \mathrm{e}$ 10 anos dos gêmeos, às vezes, também auxiliavam no cuidado. A avó materna realizava descrições superficiais e pobres, porém conversava com os gêmeos e interagia com eles de forma mais expressiva, falando alto, rindo e propondo brincadeiras.

$\mathrm{Na}$ visita dos nove meses o pouco envolvimento com os gêmeos novamente se tornou marcante. O menino (A3) estava no carrinho e movimentava-se repetidamente para frente e para trás, a ponto de mover o seu car- rinho. A mãe contou que ele fazia esses movimentos até bater com a cabeça na parede. $\mathrm{O}$ fato é relatado sem preocupações ou algum tipo de interpretação. Nas filmagens percebiase uma maior interação dos gêmeos com a avó materna, eles reagiam mais à presença dela do que a da mãe. Em nenhuma das visitas foram oferecidos brinquedos aos gêmeos e no fim do primeiro ano eles tinham vacinas atrasadas, fatos que reforçam o menor investimento nesses gêmeos. Na visita dos doze meses, em duas ocasiões A3 estava no colo de um cuidador (mãe e avó materna) e estendeu os braços para a pesquisadora para ser segurado por essa, denotando falha na relação com a figura de segurança. A irmã (B3) não mostrava essas alterações de comportamento. Com um ano ambos apresentavam desenvolvimento motor adequado.

No caso 4, até o décimo mês, a mãe cuidava sozinha das gêmeas e da filha de dois anos durante o dia e o pai auxiliava à noite. A partir dessa data, ela ingressou em um novo emprego com carga horária diária, impedindo-a de cuidar sozinha das filhas. Nos encontros dos três, seis e nove meses, a mãe era cuidadosa, as gêmeas estavam sempre com as vacinas em dia e bem asseadas, porém, ela era operativa.

Conversava pouco com as gêmeas, queixava-se de cansaço. As meninas reagiam pouco à presença materna, a mãe podia estar sentada próxima às filhas, falando e elas não olhavam em sua direção, nem a procuravam. Destacavase a diferença de vínculo entre a mãe e as gêmeas e a mãe e a filha de dois anos. A relação com as gêmeas era superficial e com a filha do meio era mais intensa e mais afetiva, sugerindo que existia uma boa capacidade de vínculo na mãe que estava inibido nesta nova relação.

$\mathrm{Na}$ visita dos seis meses ainda não eram oferecidos brinquedos para as gêmeas. Aos nove meses elas apresentavam um olhar sério e balbuciavam pouco. Mostravam interesse nos brinquedos ao seu redor e pouca resposta à presença materna. No encontro dos doze meses 
houve uma grande mudança no ambiente familiar: a mãe estava disposta, sem o ar apático dos outros encontros. Ela interagia com as filhas, falava diretamente com elas e as meninas notavam e reagiam à sua presença. A mãe se abaixou e ambas engatinharam em sua direção. As gêmeas estavam ativas, balbuciavam, buscavam brinquedos, interagiam com os pais e tinham o olhar vivo.

$\mathrm{O}$ afastamento temporal, em decorrência do novo emprego, parece ter promovido um maior investimento afetivo da mãe nas filhas. A partir dos dez meses das gêmeas, elas e a irmã de dois anos ficaram na casa de uma babá, sem outras crianças. $\mathrm{O}$ investimento de outro adulto nas gêmeas também pode ser um dos responsáveis pelo salto desenvolvimental visto dos nove para os doze meses. O pai das meninas destacava-se nas primeiras visitas por ter um olhar mais terno e afetivo para elas do que a mãe. Em todos os encontros ele buscava diferenciá-las.

Até o nono mês ele, por vezes, viajava a trabalho, referindo pouco contato diário com as gêmeas. Aos doze meses ele passava mais tempo em casa, devido à troca de emprego, aproximando-se mais temporal e psiquicamente delas. Durante as interações ele era atencioso, focava as meninas, comunicava-se com elas. No final do primeiro ano de vida, elas apresentavam um bom desenvolvimento psicomotor.

O investimento psíquico dos cuidadores adultos exerce papel central no desenvolvimento durante o primeiro ano de vida. $\mathrm{O}$ gêmeo com o menor investimento psíquico por parte dos cuidadores (A3) é o único que apresentou sintomas nítidos - movimento pendular desde os seis meses, a partir dos nove meses batia a cabeça no chão e paredes e não tinha fobia ao estranho (segundo organizador de Spitz ${ }^{12}$ ) ao final do primeiro ano de vida.

Outra evidência da importância do adulto disponível e investidor é o salto no desenvolvimento que ocorreu nas gêmeas do caso 4 , entre o nono e o décimo segundo mês. A maior disponibilidade afetiva da mãe e a entrada de uma nova cuidadora podem ser responsabilizadas por essa virada no desenvolvimento. É interessante ressaltar que nesses dois casos havia outras crianças mais velhas que auxiliavam nos cuidados dos gêmeos, o que parece não ser tão influente quanto o investimento de um adulto capaz. O que se observa é que a qualidade do investimento mais do que do tempo despendido influencia o desenvolvimento no primeiro ano após o nascimento.

\section{CUIDADORES E GEMELIDADE}

O pai do caso 2, ao ser questionado sobre a experiência da gemelidade, respondeu: "é bom ter duas, assim tem uma para cada". Essa frase sintetiza algo observado durante a convivência com as quatro famílias. Em todas há uma divisão dos gêmeos entre os pais, mesmo no caso 3 em que o pai não estava presente, a divisão ocorreu entre a avó materna e o marido dela. Essa distribuição geralmente estava associada a uma preferência, na maioria das vezes discreta, do cuidador.

Na família 1, o pai era considerado o cuidador principal de A1 e a mãe, de B1. A explicação para a divisão foi que B1 não aceitava outro tipo de aleitamento além do materno. B1 parecia-se muito fisicamente com o pai, porém a mãe não via desta maneira. $\mathrm{O}$ próprio pai comentava o fato: "ela quer que ele seja parecido com ela". No caso 2, a mãe descrevia que B2 "era um dengue com o pai" e que $\mathrm{A} 2$ a preferia, creditando a divisão às próprias gêmeas. No caso 3 havia uma divisão mais elaborada, a mãe ficava mais tempo com A3 no colo e em nossa primeira visita sua preferência era por ele. A partir dos seis meses, ela fez uma identificação por gênero com B3 e passou a descrever o filho como sendo igual ao pai, com quem tinha desentendimento importante. 
A avó materna declarava sua maior afinidade com a menina (B3) e referia envolvimento do marido com o menino (A3). A maior interação entre a avó e B3 foi observada na visita de um ano. A menina procurava a avó, respondia à suas brincadeiras, balbuciava e era risonha. A diferença de sexos entre os gêmeos favorece a individualidade e reforça a divisão de preferência entre cuidadores. No caso 4 a mãe realizava a divisão "a B4 é mais parecida com o pai, ri para todo mundo, interage, já a A4 é mais quietinha que nem eu". Na última visita, o pai inverte a atribuição e refere que B4 tem o temperamento da mãe - e essa se mostra desagradada com o comentário. O pai neste caso parece que não optou por uma delas, mas a mãe manteve durante todas as visitas sua identificação com A4.

\section{INTERAÇÃO ENTRE OS GEMELARES}

Durante as observações deu-se atenção especial à avaliação das interações entre os gemelares. Num total de 12 horas de filmagem, apenas em cinco momentos os gêmeos interagiram entre si. Com exceção dessas cinco sequências interativas, um não procurava o outro, diferentemente da forma como buscavam os cuidadores. Na maior parte do tempo eles estavam no mesmo local, muitas vezes próximos, mas não trocavam olhares ou vocalizavam um para o outro. Por vezes, um olhava para o outro, assim como se observasse um objeto, tocava ou atingia acidentalmente o outro ao se movimentar, mas não surgiam respostas. Em um momento da visita dos seis meses no caso 4, A4 chupava o dedo de B4, mas esse contato físico não desencadeou reações, uma parecendo não enxergar a outra.

Por serem escassas, cada uma das cinco sequências interativas referidas será descrita a seguir.

Os gêmeos do caso 1 estavam com nove meses e ambos demonstravam interesse por um bola, que tinha cerca de $15 \mathrm{~cm}$ de diâmetro. $\mathrm{O}$ pai já havia relatado que os dois gostavam de engatinhar atrás da bola por um corredor. Ele ofereceu o brinquedo para os meninos que passaram a seguir a bola. Inicialmente os dois engatinharam na mesma direção, mas não reagiam à presença do outro; um passava por cima do outro sem reação de ambos. Até que em um momento B1 segurou a bola e sonorizou risonho; na seqüência A1 respondeu de forma excitada, riu, vocalizou e sentado girou ao próprio redor, balançando as pernas.

Outras três interações entre os gêmeos ocorreram no caso 3 , na visita dos nove meses. Os irmãos estavam frente a frente, cada um em seu carrinho, A3 buscava intencionalmente a interação com a irmã (B3). Olhava e vocalizava para a irmã, balançava o carrinho, procurando alcançá-la. Numa dessas ocasiões os dois deram as mãos e mantiveram contato visual. Em outros dois momentos trocaram olhares e riram em resposta a vocalizações do outro.

$\mathrm{Na}$ visita de doze meses do caso 4 , as duas meninas brincavam no chão separadamente, em um determinado momento, B4 balbuciou e logo na sequência A4 fez o mesmo. Esta interação não foi tão nítida como as outras, mas pela sequência temporal e contexto foi incluída.

As observações evidenciaram escassa interação entre os gêmeos. Na maioria do tempo eles parecem não perceber um ao outro, não brincam entre si ou buscam o outro, sugerindo que eles não satisfazem suas necessidades interacionais através da relação um com o outro.

Durante o acompanhamento percebeuse que a busca dos gêmeos é pelo adulto, independente da proximidade física que possam ter com seu irmão. Algumas mães de gemelares tendem a tratar os gêmeos como um conjunto único, dispensando o mesmo tipo de cuidado à dupla sem considerar as necessidades individuais de cada. Esse tipo de funcionamento está associado a maior fadiga por parte das mães. Essas se organizam de maneira que deixam os 
gêmeos juntos em seu quarto sem a presença de um adulto a maior parte do tempo ${ }^{10}$.

$\mathrm{O}$ gêmeo (A3) que mais buscou ativamente interação com a irmã é justamente o que tem o investimento mais ineficaz por parte dos cuidadores. Possivelmente, sua busca seja compensatória a essa carência. Isso novamente reforça a necessidade da criança pelo adulto e a maior exigência sobre os cuidadores no caso de gêmeos. Talvez esse também seja um dos motivos para a divisão que os pais fazem entre os gemelares, como se para cada cuidador houvesse apenas um bebê.

\section{VERBALIZAÇÕES IDENTIFICATÓRIAS DOS ADULTOS}

As atribuições de sentido identificatório são uma das manifestações do investimento psíquico dos cuidadores nas crianças ${ }^{13}$. Os pais que mais se destacaram por terem olhar terno, cuidadoso e falarem com seus filhos foram também os que mais características lhes atribuíram. Algumas atribuições podem soar positivas: "meu gigante"; outras podem parecer negativas e gerar certa preocupação "ela é braba", "ela é mais agressiva", "a A2 quer brincar com carinho, mas a B2 vai para judiar". Ao longo do acompanhamento, observou-se que algumas atribuições se mantiveram e outras desapareceram.

Pode-se questionar qual a influência e poder dessas atribuições verbais fixas no desenvolvimento psíquico dos gêmeos. No caso 2 , as atribuições da agressividade de B2 com A2 eram freqüentes e constantes desde a visita dos seis meses. Na observação dos nove meses, percebia-se choro ou resmungo de A2 quando B2 aproximava-se. Talvez a reação de A já fosse decorrência da verbalização materna que descrevia a aproximação de B2 como ameaçadora. Estudos longitudinais de maior duração podem auxiliar a responder qual o efeito destas atribuições verbais precoces na conduta e na constituição psíquica das crianças.

\section{PLASTICIDADE E VARIABILIDADE DURANTE O PRIMEIRO ANO APÓS O NASCIMENTO}

Outro aspecto de destaque é a imprevisibilidade na evolução evidenciada a cada visita. As modificações nos cuidados e nos estímulos oferecidos aos bebês podem alterar significativamente o desenvolvimento desses $^{14}$, como ocorreu no caso 4 aos doze meses. Esse fato sugere que os bebês no primeiro ano de vida estariam sensíveis a intervenções terapêuticas precoces. Como nos primeiros anos de vida há maior plasticidade neural, talvez interferências precoces possam promover alterações estruturais, a exemplo de modelos animais ${ }^{15}$, além de comportamentais.

A pesquisa observacional acompanha a movimentação na estruturação do desenvolvimento. Estudos que iniciam nos primeiros anos de vida podem fornecer informações que no futuro serão inacessíveis à memória, marcas que estão registradas, mas não podem ser lembradas?

Sendo assim, confirma-se que o investimento psíquico do adulto nos gêmeos influencia de maneira significativa o desenvolvimento dos bebês no primeiro ano após o nascimento. Alterações na qualidade do envolvimento parental podem modificar a evolução dos gêmeos durante esse período. Destaca-se o beneficio dos gêmeos terem dois ou mais cuidadores disponíveis para atender às necessidades, ou seja, de terem um cuidado individualizado.

No primeiro ano após o nascimento, a interação comportamental entre os gêmeos é muito escassa, não sendo capazes de satisfazer afetivamente um ao outro. Observa-se que seu interesse dirige-se preferencialmente aos cuidadores, de quem dependem.

Estudos longitudinais, que iniciam nos primeiros anos de vida, podem identificar nas interações precoces fatores ambientais, protetores e de risco, capazes de influenciar o desenvolvimento psíquico dos gemelares. A par- 
tir desses estudos, intervenções de caráter profilático poderiam ser elaboradas.

Agradecimentos: Gabriela Giordani, Hugo Karling Moreschi, Maria Rita Ronchetti e
Vinicius Correa da Luz pelo auxílio prestado nas filmagens e à Associação de Psiquiatria do Rio Grande do Sul pelo incentivo à pesquisa.

\section{REFERÊNCIAS}

1. Freud, S (1895). Uma réplica às críticas do meu artigo sobre neuroses de angústia. Edição standard brasileira das obras completas de Sigmund Freud. Rio de Janeiro: Imago, 1974: (3) 141-160.

2. Lupien, SJ, McEwen, BS, Gunnar, MR, Heim, C. Effects of stress throughout the lifespan on the brain, behaviour and cognition. Nature Reviews, Neuroscience. June 2009; (10): 434 - 445.

3. Polanczyk, G, Caspi, A, Williams, B, Price, TS, Danese, A, Uher, R., Poulton, R, Moffitt, TE. Protective effect of CRHR1 gene variants on the development of adult depression following childhood maltreatment: Replication and extension. Archives of General Psychiatry. 2009; (66): 978-985.

4. Winnicott, D. W. Conozca a Su Niño. Buenos Aires: Ed. Paidos; 1970. p. 161-167.

5. Klein, M. Sobre a observação do comportamento dos bebês. In:Os Progressos da Psicanálise, Klein M et al. Rio de Janeiro: Zahar Ed.; 1969. p. 256-289.

6. Classificação Diagnóstica: 0-3: classificação diagnóstica de saúde mental e transtornos do desenvolvimento do bebê e da criança pequena. National Center for Clinical Infant Program. trad. Maria Cristina Monteiro. Porto alegre: Artes Médicas, 1997.p 45-69.

7. Soulé, M. e Cyrulnik, B. A Inteligência Anterior à Palavra, Novos Enfoques Sobre o Bebê. Porto Alegre: Artmed; 1999. p. 97-103.

8. Cozolino, L. The Developing Brain. In: The Neuroscience of Human Relationships. New York: WW Norton \& Company; 2006. p. 37-49.

9. Shore, AN. Affect Regulation and the Repair of the Self. New York: WW Norton e Company; 2003. p. 3-32.

10. Robin, M, Corroyer, D, Casati, I. Childcare Patterns of Mothers of Twins During the First Year. J. Child Psychiat. 1996; 37(4): 453-460.

11. Freitas, F, Martins-Costa, SH, Ramos, JGL, Magalhães, JA. editores. Rotinas em Obstetrícia. $5^{\text {a }}$.ed. Porto Alegre: Artmed; 2006. p. 132-140.

12. Spitz, R. O primeiro ano de vida (1965). 7ed. São Paulo: Martins Fontes; 1996. p.118-120.

13. Cramer, B, Palacio-Espasa, F. Técnicas Psicoterápicas Mãe/Bebê. Porto Alegre: Artes Médicas; 1993. p. 289-293.

14. Charlemaine, C. Les Jumeaux adultes. La Revue du Practicien. 2006; 56(20): 22612264.

15. Todeschin AS, Winkelmann-Duarte EC, Jacob MH, Aranda BC, Jacobs S, Fernandes MC, Ribeiro MF, Sanvitto GL, Lucion AB. Effects of neonatal handling on social memory, social interaction, and number of oxytocin and vasopressin neurons in rats. Horm Behav. 2009; 56(1):93-100.

Recebido em: 08/ago./2010

Modificado em 26/nov./2010 Aceito em 16/mar./2011 